\title{
Barriers of Online Education in the New Normal: Teachers' Perspectives
}

\author{
Gino G. Sumalinog \\ Cebu Normal University, Cebu City, Philippines
}

\begin{abstract}
This paper explores college instructors' lived experiences in an online learning environment. This study employed a qualitative research design with the use of interpretative phenomenological analysis (IPA). Ten college instructors from various private universities were involved in this study, and they were from learning institutions that fully implemented online learning delivery. They were trained by the institutions on how to use their learning management systems and other learning tools. Due to the restrictions caused by the COVID-19 pandemic, the data collection was done online using a semi-structured interview guide that was validated and checked by research experts. One-on-one interviews and focus group discussions were conducted until data saturation was reached. Findings revealed various barriers experienced by students. First, they experienced technological barriers, such as lack of good internet connectivity, lack of devices, and lack of technical skills in manipulating the online platforms. Second, there were attitudinal barriers, which include procrastination in doing school tasks on time, poor time management, and feeling unmotivated. Lastly, they experienced environmental barriers, which relate to noisy surroundings, lack of workspaces, and a distracting online environment.
\end{abstract}

Keywords: barriers; interpretative phenomenological analysis; online education; teachers' perspectives

\section{Introduction}

The COVID-19 pandemic not only paralyzed the world's economy; it also crippled the accustomed teaching and learning processes of schools worldwide. Partial lockdowns and closure of various learning institutions hindered students from possible transmission (Flores, 2020). As a result, school administrators have been pushed to conduct classes online despite being unprepared to shift to a new learning delivery mode. Distance learning became necessary for both educators and learners (Joaquin et al., 2020).

According to Sun and Chen (2016), online education has slowly taken over the old teaching modes and will probably continue to grow and stay. Other researchers have also revealed that online education has been adopted by mainstream 
education (Kentnor, 2015) and will continue to increase in usage (Al-Saadi, 2017). It has reshaped, refined, and restructured learning platforms. Online learning is slowly dominating the educational system (Soussi, 2020). It has become fully cyberized or shifted to online learning modality. However, despite its affordability, accessibility, and flexibility in allowing learners to save on rent, travel, and allowance costs, it should be only an alternative and not replacement to the traditional face-to-face classes. Online learning contributes positively in that it enhances knowledge dissemination. It helps students work individually, developing their self-discipline and sense of responsibility (Kuimova et al., 2015). In addition, Bezhovski and Poorani (2016) acknowledged that online learning could lead to more accessible education since costly books and other learning materials are already available with the help of the internet.

As online learning gained more popularity, the Philippines was forced to give up the accustomed face-to-face classroom setup and embrace the online or distance learning modality. In some parts of the country, blended learning has also been used as a strategy in technology-integrated classes. A few universities have also offered online courses.

However, Balatayo et al. (2021) insisted that the Philippines was not prepared for this sudden shift of the educational system from face-to-face to online learning. As such, the Philippines would need to consider several factors. These include the teachers' knowledgeability to conduct online classes, the learners' ability to cope with the situations, the efficiency of the learning environment, the country's internet speed, and cost of technological materials. (Joaquin et al., 2020). The government struggled to adjust to the abrupt change to the online modality causing the start of classes to be delayed in 2020 (Dollanganger, 2020). The sudden shift of the educational system came with some inevitable problems, including teachers' lack of technical skills and resistance to change (Coman et al., 2020). Teachers also needed training on and familiarization with the online platforms. Students were not prepared for the unexpected shift from the traditional setup to the online modality due to the country's low internet connectivity and the lack of basic skills for computer operations (Clemen et al., 2021). Moreover, there is a need to capacitate teachers and students to help them cope with the shift of the educational landscape. This could be achieved through a program that improves teachers' technical skills and which helps them to effectively communicate with their students.

In recent studies, Baticulon et al. (2020) mentioned that the online learning problems may persist for a long time and may still be exacerbated. In consonance, Balatayo et al. (2021) agreed that students experienced the topmost pain: access to and cost of the internet. For Barrot et al. (2021), students' most significant challenges were their homes, the place of learning, and their low ability to work with technology.

The abovementioned problems by previous and recent studies are what gave birth to this study. This study specifically delves into the experiences of students learning via online delivery according to their instructors' perspectives. Previous 
studies have focused only on what students had to say about their experiences, but no literature has emphasized the instructors' voices. These are the people who are aware of the problems at hand since they directly communicate with the students. The instructors' perspectives should therefore matter in disseminating research results. They possess wide and broad information since they monitor not just one but hundreds of students. Instructors are always the first to know about the stakeholders' struggles, especially that of the students. Upon completion of this research, the explored experiences of instructors could significantly inform policymakers and school administrators of the dilemma that instructors and students face. In this study, students' struggles are fully unpacked through college instructors' regular observations, since they are the go-to persons for students when they encounter problems regarding their online classes.

\section{Related Literature}

\subsection{Characteristics of Online Classes}

Online learning does not require the physical presence of the students and teachers. Chua et al. (2020) mentioned that online classes can be conducted through free platforms such as Zoom, FB Messenger, Google Classroom, and Google Meet. In 2016, Bezhovski and Poorani revealed that the trending landscape of education used by most students and teachers in the new normal included microlearning, gamification, blended learning, and personalized learning.

The influence of new technologies and intensified internet speed has led the various online education modes to grow worldwide and to become mainstream by 2025 (Palvia et al., 2018). Gallagher (2019) agreed that the online learning setup was a promising avenue to make online education completely available to all regardless of distance. After all, online learning and teaching depend greatly on well-planned content, effective interaction between teachers and their students, and well-trained and well-supported teachers.

\subsection{Benefits of Online Learning}

Despite the newness of online learning, Arkorful and Abaidoo (2014) insisted that online learning is cost-effective compared to face-to-face classes, since students do not need to travel and pay for their allowance and rental fees. As a result, online education has gained popularity in offering flexibility, affordability, and accessibility for those who struggle with travelling expenses (Sun \& Chen, 2016). Kuimova et al. (2015) believed that e-learning develops learners' skills and prepares them to become productive in today's highly technological society and workplaces. E-learning platforms enhance users' ability to cope in the real world.

Although the online learning setup has both advantages and disadvantages (Paygar, 2014), the advantages exceed the disadvantages. It is advantageous because teachers can work from home and tend to their home responsibilities. In addition to transforming teacher roles, online learning encourages students to work individually at home. Consequently, students' study habits and ways of thinking have changed (Gilbert, 2015; Suresh et al., 2018). 


\subsection{Challenges Encountered in Online Learning}

Online learning during the pandemic was also accompanied by a series of barriers for students. Baticulon et al. (2020) categorized these barriers into technological, domestic, individual, community, and institutional barriers. Some factors, particularly limited school resources, hindered the implementation of online learning (Leontyeva, 2018). Coman et al. (2020) mentioned that both students and teachers experience technical difficulties such as poor internet connectivity and lack of learning devices, especially in rural areas.

The educational flow in this pandemic period was also affected by community barriers such as electricity interruptions and limited mobility due to the lockdowns. Learners' lack of technological capabilities caused them to struggle with online educational platforms (Baticulon et al., 2020). Students who were not self-motivated felt discouraged in coping with the bulk of school tasks (Paygar, 2014). In addition, the difficulty and length of online class content did not match students' readiness and learning styles (Bao, 2020). There were also domestic barriers, which refer to an unconducive studying environment at home, conflict with family members, and financial struggles forcing them to work for their daily needs (Baticulon et al., 2020).

The presence of the teachers in the online class plays a vital role in the learning success, although this does not always guarantee seamless learning. Chua et al. (2020) revealed that most teachers lack training on using the learning platforms and lack understanding of their online learners (Bawa, 2016). Teachers are digital immigrants not able to fully operate the online platforms that their students use.

\subsection{Solutions to the Online Learning Barriers}

Although the pandemic gave rise to several problems, experts in online education management believe that teachers were still able to cope. El-Seoud et al. (2015) insisted that teachers should conduct an assessment to determine how motivated they are. They found that teachers could identify some techniques to keep the students motivated. Furthermore, they should identify the barriers and the roles they would play in the online learning environment to simulate and reflect on what strategies to use (Phan et al., 2019). In addition, they should ensure that the transition from the face-to-face delivery mode to learning through online platforms would become more successful. They should also adjust to the pace of the learners to ensure effective lesson delivery. Teachers should provide learners with timely feedback to monitor their progress (Bao, 2020).

Moreover, Coman et al. (2020) posited that teachers should make themselves available and open for communication and interactions with their students to meet problems. As they communicate, they should be more aware of the technological limitations that students may experience. In addition, students were also expected to adapt to the sudden changes. They therefore needed high-spirited and organized instructors who communicated with them consistently to provide quality and active engagement (Mangis, 2016; Tanis, 2020).

Consequently, teachers encountered many challenges as the pandemic progressed. Based on the literature, they were vulnerable to the problems brought 
about by this new learning setup. Literature has also shown that teachers are resilient and adaptable. Tubbs (2014) explained that methodology involves the methods used in performing and conducting an investigation. These methods of investigation are also called techniques that can be used in solving a problem to come up with a reliable result worthy of the time and effort spent. The literature reviewed has determined the methodology employed in this study, as will be discussed next.

\section{Methods}

This section discusses the research design, context, participants, inclusion criteria, research instrument, data gathering procedure, and the data analysis method applied in the study.

\subsection{Research Design}

This paper used a qualitative research design since it made use of words and verbatim excerpts from interviews with the participants. The study was phenomenological since it delved into instructors' experiences about how their students responded to them during online classes. In this study, participants were asked to share their lived experiences based on what they observed among their students. Interpretative phenomenological analysis (IPA) was purposefully used because the essence of the problem could only be fully grasped through acquiring instructors' lived experiences. IPA involves data coming directly from participants. IPA was employed with Smith and Osborn (2007) as proponents.

\subsection{Study Context}

The data were gathered in the Philippines, specifically in the Central Visayas region in the Philippines, where the participants lived. The Philippine educational system suddenly shifted from face-to-face learning to online learning mode due to the COVID-19 pandemic, provoking chaos and disorder in the country's socio-economic development and the world. Since contact with other people was not allowed during this time, the data were gathered virtually.

\subsection{Research Informants}

This study involved 10 college instructors from selected private universities in the Philippines who fully implemented online learning in education during the pandemic. It was decided that participants from private universities were to be selected because they were fully shifting to an online setup from their learning management system to online learning tools. The participants have been provided with pseudonyms to hide their identity. In contrast to private universities, public universities have not fully shifted to online learning because they also cater for students who opt for the modular learning modality. Data saturation was reached through the interviews with the 10 participants due to answers being repeated. These participants had been trained in using online platforms and learning management systems in their respective tertiary institutions. The sample was composed of eight female and two male instructors, whose ages ranged from 28 to 36 years old. 
Some strict inclusion criteria were followed in the selection of participants. First, participants had to have been at the university for three years or more to have enough knowledge of how the university conducted classes before the pandemic. They would thus have witnessed how the university transitioned from face-toface to online learning. Second, they had to be teaching at a university where online learning was implemented. Lastly, they had to be trained in how to use the learning management systems and other learning tools that may be incorporated in their online classes. Table 1 illustrates the demographic profile of the participants.

Table 1. Demographic profile of the participants

\begin{tabular}{|c|c|c|c|}
\hline Pseudonym & Age & $\begin{array}{l}\text { Years of teaching, } \\
\text { including during the } \\
\text { pandemic }\end{array}$ & Type of university \\
\hline 1. Ann & 36 & 7 & Private university \\
\hline 2. Ani & 34 & 8 & Private university \\
\hline 3. Joy & 29 & 5 & Private university \\
\hline 4. Angel & 34 & 7 & Private university \\
\hline 5. Roy & 31 & 6 & Private university \\
\hline 6. Vince & 29 & 11 & Private university \\
\hline 7. Berna & 35 & 8 & Private university \\
\hline 8. Divine & 35 & 8 & Private university \\
\hline 9. $\quad$ Girlie & 29 & 9 & Private university \\
\hline 10. Ferie & 28 & 5 & Private university \\
\hline
\end{tabular}

\subsection{Research Instruments and Data Gathering Procedure}

A semi-structured interview was composed in English and used in the study to guide the researcher in the entire interview process. Its content was checked and validated by three research professors to see whether the constructed questions were ideal and fit for a study that used IPA. According to Smith and Osborn (2007), the interviewer needs to establish rapport. The order of the questions was not important and the researcher was free to probe areas of interest and concern. As a result, six questions of interest were asked to the participants in no particular order, as suggested by Smith and Osborn (2007). (See Appendix 1 for the interview questions.) The instrument was meant to explore the participants' observed phenomena in implementing an online learning modality for the first time due to the pandemic. The same questions were used for the focus group discussion, in which all of the participants attended. The participants were asked to give informed consent to participate in the study. They were then asked when they would like to be interviewed. They could choose the time, the mobile network, and the computer application to use for the online interview and focus group discussion. The focus group discussion was also conducted online using the Zoom app to personally obtain information from the 10 participants where they could validate and confirm the information given. The interviews and focus group discussion were recorded and transcribed. There was no need for translation since participants responded in English. All data are kept confidential and were stored on the researcher's laptop, making sure that no one has access to the data. 


\subsection{Data Analysis}

This study followed the IPA protocol of Smith and Osborn (2007), which consists of five steps, namely:

a) Looking for themes in each case. In this step, the transcript was read and reread several times. The researcher immersed themself in the data to gain familiarity with the participants' responses. Beside each transcript was a margin where anything significant, engaging, and striking stated by the participants was written down.

b) Looking for connections. In this stage, the emerging themes were listed on the right-hand side of the transcripts. After this, the themes were clustered based on their connections. The clustered emerging themes were compared again with the transcript to ensure all other related words were included.

c) Compiling a table of themes. This stage involved displaying all the themes, which had been clustered and labelled coherently according to connections. This process was done with care in order to ensure that the themes would be represented in the verbatim excerpts and not be influenced by researcher bias.

d) Compiling a master list of themes for the group. As the analysis progressed following IPA, a final list of themes was compiled.

e) Writing reports. This step was concerned with writing reports for publication using the master list of themes. The themes were translated into narrative accounts. Verbatim excerpts from the participants' narratives were incorporated into the write-up to confirm the researcher's interpretation.

\section{Results and Discussion}

After an extensive analysis of the participant responses, three superordinate themes on instructors' perspectives regarding the barriers of online education emerged. These are: (a) technological barriers, (b) attitudinal barriers, and (c) environmental barriers.

\subsection{Theme 1: Technological Barriers}

Philippine schools did not have the necessary support during the pandemic to handle an online learning setup due to insufficient facilities. The country was not prepared and capacitated instructors to handle online classes due to varied reasons. In this study, participants commented that their students experienced some technological barriers. These included lacking devices to use for online learning, internet connectivity being slow, and not possessing enough technical skills to perform the tasks. These technological barriers surfaced regularly during the interviews.

\subsubsection{Lack of devices}

Participants mentioned that students lacked some learning devices, especially those who resided in rural areas. The majority of students just used their mobile phones, and not all of their phones were high-end devices. Therefore, these devices did not have sufficient storage capacity. Students also struggled multitasking with only their mobile phones, and some phones could not play 
videos required for research tasks (Bezhovski \& Poorani, 2016). Even highly technological countries also struggled with lack of learning devices. In California, roughly 1.2 million public school learners did not have devices for the sudden learning modality shift (Salman, 2020). The same happened in Indonesia. Its distance learning was greatly hampered by a lack of devices (Eloksari, 2020). Participants also complained about their students not finishing an activity on time. This is because drawing, typing and videoing, and editing tasks using mobile phones required much time due to their small screen size. The participants added that students were not always able to attend whole online classes from start to finish using their mobile phones alone, for the phones could become too warm during classes of an hour duration. According to Ann and Ani:

"A phone is not ideal for online classes. It has a small screen and limited capability."

"They have a hard time working by their phones. Some phones do not have editing and drawing features."

Using a mobile device in all the tasks across all the courses was another challenge. The participants shared that some of their students had difficulty working with the limited capabilities and features of mobile phones. Ideally, they should use computers so that they can do more than just type. Thompson (2020) revealed that students who use computers for their online classes are more advantaged than those with no access to computers. With computers, students enjoy the privilege of working with larger screens, clearer visuals, more extensive storage, and familiar commands from the easy-to-hover keyboards and relatable basic computer operations.

\subsubsection{Lack of good internet connectivity}

The Philippines needs to consider its internet speed for online education to succeed (Joaquin et al., 2020). Baticulon et al. (2020) agreed that students were not ready for the sudden shift from face-to-face classes to online learning due to the low internet connectivity. The slow internet was a concern for every user. Participants noticed that students were slowly lost during video conferencing, though they could reconnect after a minute or two. Unfortunately, some of them lost their internet connection completely and never had the chance to re-join. Students and instructors experienced poor internet connectivity. However, participants noted that some students were consistently present throughout the online class discussion, although they lagged. Their audio very often faded while their video froze. The slow internet connectivity also interrupted students' participation during interactions, making it difficult for instructors to interact with students and to hear their responses. Joy, Angel, and Roy shared the following:

"Some students get disconnected because of their slow internet."

"There are few whose connectivity is stable, but they lagged most sometimes. It was hard to get the answers."

"They get disconnected and connected again. The same thing happens throughout." 
With the poor internet connectivity, instructors needed to repeat information whenever students requested them to do so. As a result, some of the allotted time was wasted. In reality, working with a slow internet connection can be frustrating because some tasks can disappear when the webpage does not correctly load the information. Some tasks cannot be done without internet connectivity, for the internet can increase the richness of the information being sought. Slow internet was not a problem only in the Philippines. Even schools in technologically advanced US states such as California had some issues with internet access when the pandemic started (Salman, 2020). Poor internet connection has become a common struggle for learners (Eloksari, 2020). Lastly, participants complained that some students sometimes failed to submit larger files because the internet speed was not strong enough to deliver the submission.

\subsubsection{Lack of technical skills}

Student tasks submitted to instructors have shown that some students lacked some technical skills, especially in creating graphics and videos. Baticulon et al. (2020) affirmed that learners lacked technological capabilities and struggled with the online educational platform. According to the participants, this problem was true since students seldom make videos and graphics using their phones and laptops during face-to-face classes. Before the pandemic, students often worked manually with visible and tangible materials that do not require any technological skills. Some participants indicated that they were considerate in such cases, since the problem may have been caused by the inability of devices to perform specific tasks. Moreover, in this online setup, everything was done online, so students were in the process of learning and familiarizing themselves with the tools to use. Students lacked the essential skills for computer operations (Dollanganger, 2020). Vince and Berna mentioned:

"Not all know how to use their gadgets."

"Some of them are still exploring. The students are in the process of discovering the use of their learning tools."

The participants also mentioned that some students did not have the necessary skills, not because they did not have enough exposure, but simply because they were not interested and were not motivated to work in an online environment. Since the pandemic happened very quickly, most students had to explore this new setup since none had prepared for it. Some participants were digitally illiterate and could not fully operate their students' online platforms (Bawa, 2016). Instructors lacked technical skills and were resistant to change. They also needed training and familiarization with the online platforms (Burns, 2019). There was a need to capacitate the instructors to help them cope with the educational landscape's sudden shift. This could be achieved through a program to improve instructors' technical skills and to help them effectively communicate with their students.

\subsection{Theme 2: Attitudinal Barriers}

The newness of the online learning setup could develop the skills of instructors and students to make them productive despite the crisis. In delivering what was expected, participants noticed some behavior that manifested when students were 
given online tasks. Some students procrastinated and exhibited poor time management, especially during the submission deadlines. Others were unmotivated. Instructors should adjust to the learners' pace to ensure effective lesson delivery and to provide the learners with timely feedback to check their progress.

\subsubsection{Procrastination}

Procrastination is one of the significant factors causing students in an online environment to fail. Students procrastinate by putting off learning tasks until they become too difficult to catch up (Burns, 2019). During online tasks, the participants noticed that some students were procrastinating. They realized this when they made some follow-ups of the tasks to be submitted. The students did not immediately work on the tasks assigned to them. As a result, their academic performance decreased. Divine and Ferie expressed:

"There was a clear indication of procrastination because they do not submit on time, and they complain about the bulk of work that they had to do. The tasks were not given altogether at the same time."

"When asked about their tasks, they had no clear answers. They were not done yet."

Based on the participants' responses, it could be said that they had a problem in letting the students work and submit their tasks on time. Though this was completely acceptable because the students were not used to working online, the participants disagreed that students should delay doing their tasks. Education is a dynamic and continuous process. Students also tended to procrastinate because they lacked the necessary devices and other online learning support. According to Cerezo et al. (2017), learning progresses from one lesson to another. Procrastination could thus cause slow progress in students' submission of tasks. Some students were guilty of procrastinating, but they still honestly shared with their instructors that they would prefer working on tasks together a day or days before the deadline submission. They were worried about the bulk of tasks they had to do. In consonance, Burns (2019) concurred that procrastination resulted in stress, anxiety, shame, and self-doubt in completing online tasks. According to the participants, the students were not as mentally active as they were physically active during the pandemic.

\subsubsection{Poor time management}

The participants mentioned that the outputs they required from the students were sometimes submitted only minutes before the deadline. Sometimes, work was even submitted after the due dates. The participants insisted that this was a clear indication of poor time management. Poor time management is one of the problems that impedes students' learning, and it happens when students fail to schedule their tasks properly (Sellers, 2020). Based on the participants' experience, their students would not submit what was required on time. It was evident that students did not manage their time well in completing the tasks assigned to them. The participants said that most of the students were focused on the tasks, yet they failed to allocate the right amount of time to be spent on each task. They spent more time on the tasks that interested them. Ann and Girlie shared: 


\begin{abstract}
"They had no proper time management because this learning setup is new to them. I noticed that they always submit late."

"My students do not schedule their tasks. They often forget submission time."
\end{abstract}

The verbatim excerpts of the participants show how their students mismanaged their time. Nonetheless, experts believe that poor time management can still be rectified. Students can do so by efficiently drawing up schedules for work and study (Kokemuller, 2020). Students can manage their time by scheduling short breaks in between work periods. In addition, students taking online classes might add a prompt at their working stations to remind them to take a one-minute break for every half an hour of sitting (Mangis, 2016). As for instructors, they may directly inform their students and give them tips on managing their time.

\title{
4.2.3 Feeling unmotivated
}

In El-Seoud et al.'s (2015) study, instructors conducted assessment to determine how motivated their students were. Prior to the pandemic, students were high-spirited, as indicated by the participants. However, students lost their motivation as the pandemic continued. The participants shared that before and after classes, they motivated their students to keep going since online education required students to be independent and self-motivated (Shore, 2020). However, the students were not motivated due to challenging home circumstances. These included financial instability, joblessness of parents, and cost of the online materials. Participants also noticed that some students were absent or silent during online classes. Angel and Roy commented:

"My students lack motivation. Some of them are always absent."

"Many of their parents are unemployed; that's why they are very affected."

From these responses can be seen that participants knew their students' struggles. Nonetheless, they continued to try to motivate them. Some students wanted to discontinue their studies and saw no reason to continue, especially since time was against them. Students also lost their enthusiasm, optimism, and interest in coping with the new technology to be used, especially since online learning would probably remain even after the pandemic (Sim et al., 2020). Despite these negative experiences, students should continue and need to be motivated and stimulated (Tanis, 2020).

\subsection{Theme 3: Environmental Barriers}

Participants also identified environmental or domestic factors that hindered the learning process and contributed to students' learning difficulties. These included an unconducive studying and learning environment at home, conflict with family members, and financial struggles forcing them to work to earn an income. Because of the many factors, participants needed to identify the barriers and their roles in the learning environment. However, the they understood that the pandemic had just begun and that these barriers were inevitable. 


\subsubsection{Noisy environment}

Keeping a workspace free of noise and distractions could result in student productivity and concentration (Hecht, 2020). Sellers (2020) agreed that students who engage in online learning modalities should have a workspace that lessens distractions but fosters concentration. In contrast, the participants shared that they heard background noise from the students' end while conducting online classes. The noise was from food vendors, garbage collectors, neighbors, other family members, and nearby establishments. These noise barriers were heard specifically when it was students' turn to speak, when their microphone was intentionally turned on. The participants' observations were confirmed when students asked them to repeat a portion of the discussion because they did not hear them due to the noise disturbance. Even the noise caused by rainfall contributed to the problem. The problem can only be solved when students can find a quiet place to study. Angel and Vince shared:

"There is a noise that I can hear at the students' end. They are distractions, especially the rains and the neighbors."

"The class is disturbed when the noise interferes. I heard vendors' voices and other background noise."

The verbatim excerpts of the participants support their claim about the noise coming from the students' end. Despite the distracting noise, participants understood that no one had prepared for this pandemic and that not all students had a study place free of noise. To counter this challenge, Brooks (2018) suggested that instructors may consider investing in noise-canceling headphones.

\subsubsection{Lack of workspaces}

Online learning requires students to spend more time and energy than in the face-to-face setup (Kokemuller, 2020). This means that students would need a conducive place. However, according to the participants, some students could not even find a quiet place at home to attend their online classes. As a result, they would have to endure all the noise for the sake of learning. This problem could not be avoided since most students live in crowded areas where they are separated from their neighbors only by walls. According to the participants, their students could also not use the isolated corners of their houses because internet connections were only speedy in open places. Ani, Ann, and Joy expressed:

"When called to participate, students would still need to find a conducive area of their house, for most of them do not have workspaces."

"Most of my students had no workspace. They only occupy any area of the house where noise is heard less."

"They could not exhaust for means to find a good workspace since the internet is only speedy in open places."

The participants had witnessed how students struggled to find a suitable place to be their study and workspace. In consonance, McKie (2020) revealed that $72 \%$ of the graduate students participating in her study were affected by lack of workspace to study. There was a need for students to secure a conducive corner at home where they could study. 


\subsubsection{Distracting online environment}

Working on tasks online requires a lot of focus and determination since the internet and the online world have too much to offer. Unfortunately, online classes can be conducted through free platforms such as Zoom, FB Messenger, and other social media sites with all the desirable features that can distract students (Chua et al., 2020). The trending landscape of education that most students and instructors in the new normal used include gamification where students may play longer compared to the traditional classroom setup (Coman et al., 2020). The participants' students shared with them that they frequently became so engrossed with the tasks they were working on that they found themselves lost in the internet world. The participants shared that their students did not notice that they were already surfing the web. The participants added that sometimes students would leave their work and spend time checking their social media accounts and watching viral videos (Sellers, 2020). As a result, students lost attention and started giving up the tasks. The participants added that students who became distracted while taking online classes would neglect their homework and leave the study session early (Abel, 2020). Ferie and Girlie expressed:

"Our students would sometimes visit their social media sites until they get distracted and forget to go back to their work."

"My students are easily lost in the online world. Their time is spent exploring and checking their social media sites."

The narratives of the participants show their profound observation towards their students' attitude when being online. Sometimes, students would spend too much time working on a single task because their concentration got fragmented. To solve the problem, students should find a better study area. Perhaps they should not study in the kitchen or the dining area, where they might sit on a comfortable couch with the TV distracting them. In short, they need to identify the places that could distract them and avoid these before they lose their attention (Love, 2020).

From the participants' perspective, students' struggles should be heeded, since online education is growing worldwide (Palvia et al., 2018). This online learning setup is a promising avenue to start a complete online education that could be available to all regardless of distance and the country's resources (Gallagher, 2019). It is cost-effective compared to face-to-face classes, for students do not need to travel and pay for their allowance and rental fees (Arkorful \& Abaidoo, 2014). Students need a little more time to accept the new direction the world's educational system is taking. With these new methods, students' study habits and way of thinking should change too (Suresh et al., 2018).

\section{Conclusion}

Online learning during the COVID-19 pandemic came with many barriers that tested students' resilience, as witnessed by their instructors, who were also their constant guide. These barriers were new since the sudden change of educational modality caught both students and instructors off-guard and unprepared. As the need to adapt to a new system and learning modality rose, even the people affected by the barriers chose to exhaust all means just to get over them. Despite the effort to fill the gap, the barriers emerged and became stumbling blocks to how 
the teachers delivered the instruction and managed their classrooms. By sharing their lived experiences, participants could share the various barriers they faced during the pandemic. It can be concluded that universities still have many issues to attend to and innovations to create to make the online teaching and learning process successful. Although universities responded to the need of the times, their efforts were unfortunately not enough. The purpose of the study was to expound on instructors' perspectives of online education, and has resulted in an intensive analysis and examination of the barriers. In the long run, the barriers should be addressed through feasible solutions. For future research direction, university administrators' perspectives may by explored to view and examine their capabilities in meeting the needs of university stakeholders.

\section{Recommendations}

The Commission on Higher Education of the Philippines should formulate online learning guidelines based on instructors' perspectives, for instructors are deeply immersed and involved in online education. At the institutional level, administrators may gather instructors in a forum and validate the results of studies that have highlighted the barriers of online learning based on the instructors' perspectives. Researchers who plan to research a topic similar to the topic in this paper may involve instructors both from private and public universities.

\section{Implications}

The results of the study yielded a series of insights. When presented in the proper forum, this study can inform and guide school leaders to craft online class guidelines that can cater to the majority of struggling students due to the new online setup. It can directly inform the instructors on the struggles of the students. As a result, instructors may become more flexible and understand the unexpected situations that students may encounter. This study sets the stage for researchers to go deeper and to focus on the emotional and phenomenological impact that this new online setup may have on the struggling students and the instructors, who are having a hard time adjusting to the new normal. To realize the positive impacts that this paper may offer, leaders and administrators need to proactively address barriers of online education as soon as possible.

\section{References}

Abel, A. (2020, December 9). Help your students deal with digital distractions. Collegiate Parent. https://www.collegiateparent.com/student-life/dealing-with-digitaldistractions/

Clemen, I. G., Ali, H., Abdulmadid, A-N., \& Jabbar, J. H. (2021). Education during COVID-19 era: Are learners in a less-economically developed country ready for e-learning? $\quad Z B W$ - Leibniz Information Centre for Economics. https://www.econstor.eu/bitstream/10419/234960/1/Education\%20During\%2 0COVID-19\%20Era\%20Readiness\%20of\%20Students\%20in\%20a\%20LessEconomically\%20Develo.pdf

Al-Saadi, N. (2017). E-learning and its impact on future generations. Journal of Information Technology Education: Research, 17, 187-160. http://www.informingscience.com/Publications/3524 
Arkorful, V., \& Abaidoo, N. (2014). The role of e-learning, advantages, and disadvantages of its adoption in higher education. International Journal of Education and Research, 2(12), 397-410. https://www.ijern.com/journal/2014/December-2014/34.pdf

Balatayo, S., Almreia, T., Alborte, S., Nobleza, J., Ebora, M., \& Oducado, R. (2021). Barriers towards online learning among graduate students in nursing in a Philippine higher education institution during the global COVID-19 outbreak. SSRN. https:/ / ssrn.com/abstract $=3927626$

Bao, W. (2020). COVID-19 and online teaching in higher education: A case study of Peking University. Human Behavior \& Emerging Technologies, 2, 113-115. https://doi.org/10.1002/hbe2.191

Barrot, J. S., Llenares, I. I., \& Del Rosario, L. S. (2021). Students' online learning challenges during the pandemic and how they cope with them: The case of the Philippines. Education and Information Technologies 26, 7321-7338. https://doi.org/10.1007/s10639-021-10589-x

Baticulon, R. E., Alberto, N. R., Baron, M. B., Mabulay, R. C., Rizada, L. T., Sy, J. J., Tiu, C. S., Clarion, C. A., \& Reyes, J. B. (2020). Barriers to online learning in COVID-19: A national survey of medical students in the Philippines. Medical Sciences Educator, 2-19. https://doi.org/10.1101/2020.07.16.20155747

Bawa, P. (2016). Retention in online courses: Exploring issues and solutions - A literature review. Sage Journals, 6(1), 1-11. https://doi.org/10.1177/2158244015621777

Bezhovski, Z., \& Poorani, S. (2016). The evolution of e-learning and new trends. International Knowledge Sharing Platform, 6(3), 50-57. https://www.iiste.org/Journals/index.php/IKM/article/view/29274/30063

Brooks, M. (2018, February 12). Five tricks for blocking outside noise so students can focus. Enlightium Christian Academy.

https://www.enlightiumacademy.com/blog/parent-center/entry/five-tricksfor-blocking-outside-noise-so-students-can-focus

Burns, M. (2019, November 3). I will get to it tomorrow: Procrastinating in online learning. eLearning Industry. https://elearningindustry.com/procrastination-in-onlinelearning

Cerezo, R., Esteban, M., Santillan, M., \& Núñez, J. (2017). Procrastinating behavior in computer-based learning environments to predict performance: A case study in Moodle. Frontiers in Psychology, 8, 1-11. https:// doi.org/10.3389/fpsyg.2017.01403

Chua, E. R., Sibbaluca, B. G., Miranda, R. D., Palmario, G. B., Moreno, R. P., \& Solon, J. T. (2020). The status of the implementation of the e-learning classroom in selected higher education institutions in Region IV-A amidst the COVID-19 crisis. Journal of Critical Reviews, 7(1), 253-258. http://doi.org/10.31838/jcr.07.11.41

Coman, C., Tiru, L., Schmitz, L., Stanciu, C., \& Bularca, M. (2020). Online teaching and learning in higher education during the coronavirus pandemic: Students' perspective. Sustainability, 12, 2-24. https://doi.org/10.3390/su122410367

Dollanganger, C. (2020, October 29). Philippines: The rich and poor divide in distance learning. The News Lens. https:/ / international.thenewslens.com/article/142537

Eloksari, E. (2020, December 1). Poor internet connection, lack of devices hinders online learning ministry. The Jakarta Post.

https:// www.thejakartapost.com/news/2020/12/01/poor-internet-connectionlack-of-devices-hinder-online-learning-ministry.html

El-Seoud, M. S., Taj-Eddin, I. A., Seddiek, N., El-Khouly, M. M., \& Nosseir, A. (2015). E-learning and students' motivation: A research study on the effect of e-learning on higher education. International Journal of Emerging Technologies, 9(4), 20-26. http://doi.org/10.3991/ijet.v9i4.3465 
Flores, M. (2020). The COVID-19 pandemic and its effects on teacher education. European Journal of Teacher Education, 43(4), 453-456.

https://doi.org/10.1080/02619768.2020.1824253

Gallagher, S. (2019). Online education in 2019: A synthesis of the data. VOCED Plus. https://www.voced.edu.au/content/ngv\%3A84464

Gilbert, B. (2015). Online learning revealing the benefits and challenges (Master's thesis). St. John Fisher College, Rochester, New York. https:// fisherpub.sjfc.edu/education_ETD_masters/303

Hecht, D. (2020, August 28). Students, how will your workspace affect your productivity during remote learning? Tap into East Brunswick. https://shorturl.at/bgwCD

Joaquin, J., Biana, H., \& Dacela, M. (2020, October 22). The Philippine higher education sector in the time of COVID-19. Frontiers in Education. https:// doi.org/10.3389/feduc.2020.576371

Kentnor, H. (2015). Distance education and the evolution of online learning in the United States. Curriculum and Teaching Dialogue, 17(1), 21-34. https://digitalcommons.du.edu/law_facpub/24/

Kokemuller, N. (2020). Negative effects of online courses. Seattle. https://education.seattlepi.com/negative-effects-online-courses-1094.html

Kuimova, M., Kiyanitsyna, A., \& Truntyagin, A. (2015). E-Learning as a means to improve the quality of higher education. SHS Web of Conferences, 28(1), 1-5. https://doi.org/10.1051/shsconf/20162801129

Leontyeva, I. (2018). Modern distance learning technologies in higher education: Introduction problems. EURASIA Journal of Mathematics, Science and Technology Education, 14(10), 1-8. https://doi.org/10.29333/ ejmste/92284

Love, A. (2020, October 9). How to stay focused and avoid distractions in online classes. Southern Utah University. https:// shorturl.at/joMO8

Mangis, J. (2016). Online learning and the effects on functional health: A pilot study. (Master's thesis). Eastern Washington University.

https:/ / dc.ewu.edu/cgi/viewcontent.cgi?article $=1386 \&$ context $=$ theses

McKie, A. (2020, September 3). Lack of study space and poor connections hinder online learning. The World University Ranking.

https:// www.timeshighereducation.com/news/lack-study-space-and-poorconnections-hinder-online-learning

Palvia, S., Aeron, P., Gupta, P., Mahapatra, D., Parida, R., Rosner, R., \& Sindhi, S. (2018). Online education: Worldwide status, challenges, trends, and implications. Journal of Global Information Technology Management, 21(4), 233-241. https://doi.org/10.1080/1097198X.2018.1542262

Paygar, A. (2014). Challenges and opportunities of online learning in developing countries with a specific focus on Liberia (Master's thesis). Bemidji State University, Bemidji, Minnesota.

https://www.bemidjistate.edu/academics/departments/political-science/wpcontent/uploads/sites/40/2015/05/paygar-thesis.pdf

Phan, Q. T., Ngo, T. T., \& Phan, T. T. (2019). Developing the information technology application competence of instructors in online learning. International Journal of Applied Research in Social Sciences, 1(4), 124-137. https://core.ac.uk/reader/327322830

Salman, J. (2020, June 4). Hundreds of thousands of students still can't access online learning. The Hechinger Report. https:// shorturl.at/nxET6

Sellers, E. (2020). Poor time management in online learning. Seattle PI. https://education.seattlepi.com/ poor-time-management-online-learning1435.html 
Shore, J. (2020). Problems in online classes. Seattle PI. https:/ / education.seattlepi.com/ poor-time-management-online-learning1435.html

Sim, S. P., Sim, H. P., \& Quah, C. (2020). Online learning: A post COVID-19 alternative pedagogy for university students. Asian Journal of University Education, 16(4), 137-151. https://doi.org/10.24191/ajue.v16i4.11963

Smith, A., \& Osborn, M. (2007). Interpretative phenomenological analysis. http://med-fomfamilymed-research.sites.olt.ubc.ca/files/2012/03/IPA_Smith_Osborne21632.p df

Soussi, K. (2020). Web-based learning: Characteristics, practices, challenges, and recommendations. International Journal of Science and Research, 9(3), 936-943. https://doi.org/10.21275/SR20312135240

Sun, A., \& Chen, X. (2016). Online education and its effective practice: A research review. Journal of Information Technology Education: Research, 15, 157-190. http:/ / www.informingscience.org/Publications/3502

Suresh, M., Priya, V., \& Gayathri, R. (2018). Effect of e-learning on academic performance of undergraduate students. Drug Invention Today, 10(9), 1797-1800. https://www.researchgate.net/publication/327202545_Effect_of_elearning_on_academic_performance_of_undergraduate_student

Tanis, C. J. (2020). The seven principles of online learning: Feedback from faculty and alumni on its importance for teaching and learning. Research in Learning Technology, 28(1), 1-25. http:// doi.org/10.25304/rlt.v28.2319

Thompson, V. (2020). Why are computers a good tool for college assignments? Seattle PI. https://education.seattlepi.com/ poor-time-management-online-learning1435.html

Tubbs, N. (2016). Epistemology as education: Know thyself. Education Sciences, 6(4), 41. https://doi.org/10.3390/educsci6040041 
Appendix 1

Research Instrument

1. What can you say about our country's sudden shift from face-to-face classes to online education due to the pandemic?

2. Can you say that the students were prepared for the sudden shift from face-to-face to online learning education?

3. What are the barriers that hinder the success of your online classes?

4. How did the barriers affect the students' attendance at your classes?

5. Can you explain the barriers comprehensively?

6. Can you please give the details of the barriers that you have mentioned? 